\title{
Screen Present and Fictional Present
}

\author{
Robin Le Poidevin \\ University of Leeds \\ The School of Philosophy, Religion and History of Science \\ Leeds, West Yorkshire \\ United Kingdom of Great Britain and Northern Ireland \\ R.D.LePoidevin@leeds.ac.uk
}

\section{Article info}

CDD: 115

Received: 13.11.2016; Accepted: 17.11.2016

DOI: http://dx.doi.org/10.1590/0100-6045.2016.V39N4.RP

Keywords:

Time in Fiction

Presentism

Openness of the Future

\begin{abstract}
I intend in this paper to explore the possible consequences for our understanding of fiction of a particular view of the nature of time, namely the hypothesis of the open future. The kind of fiction we will particularly concerned with is film, which provides a convenient way of focusing the general issue I want to raise here. The issue could also be raised in relation to theatre and certain types of novel, but there are nevertheless some disanalogies between film and these other art forms, and I shall indicate these below. The essay is intended as an exercise in bringing metaphysics and aesthetics together, to the benefit (I hope and trust) of both.
\end{abstract}

\section{Fiction and the open future}

I intend in this paper to explore the possible consequences for our understanding of fiction of a particular view of the nature of time, namely the hypothesis of the open future. The kind of fiction we will particularly concerned with is film, which provides a convenient way of focusing the general issue I want to raise here. The issue could also be raised in relation to theatre and certain types of novel, but there are nevertheless some disanalogies between film and these other art forms, and I shall indicate these below. The essay is intended as an exercise in bringing metaphysics and

Manuscrito - Rev. Int. Fil. Campinas, v. 39, n. 4, pp. 315-330, out.-dez: 2016. 
aesthetics together, to the benefit (I hope and trust) of both.

Let us begin, then, with a brief and intuitive description of the open future hypothesis. According to this conception, there is an important ontological difference between the present and past on the one hand, and the future on the other, in that whereas there is a fact of the matter as to both what is happening, and what has happened, there is no fact of the matter as to what will bappen..$^{1}$ The future is nothing but a set of possibilities, none of which is as yet actual. And this is not simply a matter of ignorance: it is not that there is an actual future, but we don't know what it will be. Even an omniscient being could not know what will happen, for there is no fact to be known. The passage of time, on this view, is a matter of becoming: of things coming to exist, of the indeterminate becoming determinate. Once something is present, and then becomes past, there is an ineradicable truth, that such-andsuch an even once happened. And this remains the case even if we lose track of any evidence that it once happened. Proponents of this view tend to emphasise that it represents our intuitive, pre-theoretical beliefs about time.

Now consider fictions, and in particular narrative fictions, that is, those which display a temporal structure. Should we bring our understanding of time as it actually is to our interpretation of fictional time? If, for instance, we

\footnotetext{
${ }^{1}$ For the purposes of this paper, I am characterising the open future in terms of a failure of bivalence for future-tensed statements, as this is perhaps the simplest, most intuitive formulation. It is also the one associated with Aristotle's famous 'sea battle' discussion of the future in De Intepretatione (Ackrill (1963)). However, there is a way of conceiving of the unreality of the future which does not restrict bivalence in this way. Suppose that determinism is true: that is, that the state of the universe at any one time together with the laws of nature necessitates the state of the universe at any given later time. Bivalence will thus hold for future-tensed statements. But the future could still be unreal in this sense: that it does not provide truth-makers for futuretensed statements. Rather, it is present fact which determines their truth-value. The question of the reality of the future could thus be posed as a question about the nature of the truth-makers for future-tensed statements, rather than bivalence. However, as I want to keep the characterisation as intuitive and theoretically unladen as possible, I confine myself here to the question of the determinacy of truth-value. For a historically-informed discussion of bivalence and the open future, see Lucas (1989). For an examination of the open future and the passage of time in terms of a 'growing block' of reality, see Dainton (2010), Chapter 6.
}

Manuscrito - Rev. Int. Fil. Campinas, v. 39, n. 4, pp. 315-330, out.-dez: 2016. 
are open future theorists (of an intuitive, not necessarily a particularly sophisticated kind), should we take the fictional future to be open? Two considerations suggest that we should.

First, there is what we might call the principle of fictional conservativism. This is the principle that we should not assume that the fictional world is radically unlike ours unless there are clear indications that it is. Fictions in which magic features, or time travel, or instantaneous and discontinuous movement from one place to another, or in which characters radically alter their shape at will, or possess anti-gravitational powers, or the capacity to perceive the future, are fictions which clearly indicate that the laws of the actual world do not apply. But in the absence of any indication to the contrary, we will assume that fictional characters will be similarly constituted, psychologically and physically, to us, and that the fictional world will be subject to the familiar laws of motion, gravity, energy conservation, and so on (it does not matter that we may have only the haziest notion of these laws - we can generally recognise a violation of them when we see one on screen). This is not to say, however, that any well-confirmed scientific hypothesis can imported into any given fiction. There is no point, for example, in insisting that the ideal gas laws obtain in Gunfight at OK Corral, since they play absolutely no role in our understanding of the enfolding events (though they would certainly play a role in a scientific understanding of an actual gunfight). The background conditions are those that it would be generally agreed obtain in the actual world (that people typically have just one nose, for example, or that things fall to the ground when dropped). These things make a difference to what the fictional world would seem like to an observer. Now, the open future hypothesis is held, with some justification, to capture our intuitive beliefs about time, and so could be represented as part of a shared understanding of the actual world which can legitimately be imported into the fictional world. (It will now be apparent, perhaps, why I wanted to characterise the open future hypothesis in fairly simple, intuitive terms. The more theoretical complexity we build into the view, the less plausible it is that it could be part of our understanding of the fictional world.)

A second reason for taking fictional time to be characterised by the open future hypothesis is that time's passage is supposed, by those who believe in it, to be not just an accidental and purely contingent feature of time, but as essential to it. Without passage, a world is not a temporal one. Passage is thus

Manuscrito - Rev. Int. Fil. Campinas, v. 39, n. 4, pp. 315-330, out.-dez: 2016. 
thought to have a quite different status from, say, certain geometrical features of time (its being continuous rather than discrete, or having an intrinsic metric as opposed to a conventional one). What does passage consist of? Again, the inclination is to go for an essentialist view. For the open future theorist, the passage of time is things coming into being, where before they were quite indeterminate. And truths we take to be necessary will be true of counterfactual situations. Since fictions are counterfactual situations, necessary truths will hold good. (Although perhaps this too needs qualifying with a 'unless there are clear indications to the contrary'. It might be an important component of some fiction that the usual rules of arithmetic do not apply. Some fictions, then, perhaps deserve to be classified as impossible fictions'. $\left.{ }^{2}\right)$

Proponents of the growing block hypothesis, then, have good reason to interpret the time of narrative fictions as conforming to that hypothesis. This now leads to the following question: since the open future entails an objective present, if fictional time has an open future, when is the fictional present? As we are concerned with film, let us focus the question on the relation between the fictional present and what we call the screen present, that is, the images that are being projected onto the screen at any one moment. Does the fictional present coincide with the screen present, or is it always after the screen present?

We can, I think, rule out straightaway the suggestion that the fictional present is always earlier than the screen present, that what is on the screen lies in the fictional future. For if the fictional future is open, then then what is represented on the screen does not fictionally exist - it is still indeterminate. But this absurd. That would mean that there is nothing to present on the screen - it would have to be a blank! Far more plausible to say that the images appearing on the screen represent determinate fictional fact.

That leaves two possibilities: screen present represents what is fictionally past, and screen present represents what is fictionally present. We will take

\footnotetext{
${ }^{2}$ Impossible fictions, obviously enough, pose a challenge for accounts of fictional truth in terms of possible worlds. For contrasting strategies for dealing with apparently impossible fictions, see Lewis (1978), (1983) and Bourne and Caddick Bourne (2016), Chapter 12. The latter work also contains an extended discussion of the notion of a fictional past, present and future.
}

Manuscrito - Rev. Int. Fil. Campinas, v. 39, n. 4, pp. 315-330, out.-dez: 2016. 
these two in turn. First, though, I want to consider an important disanalogy between film and the novel, which means the answer to the question just posed is not as obvious as it might appear to be.

\section{Verbal inflexion and screen tense}

With novels, the equivalent of screen present is, presumably, what one is reading. And so we can pose the question, what is the relationship between the fictional present and the reading present? And here an answer seems pressed on us by the verbal inflexion of the sentences. Typically, but by no means invariably, the narrative is in the past tense: 'She wandered onto the balcony, and saw in the distance the unmistakable profile of the mountain, whose summit was even at the height of summer covered with snow.' The natural inference to draw from this is that the events narrated are in the past. When a novel is written in the present tense, as in the historical novels of Philippa Gregory, for example, the effect is quite striking, and draw one into the action. The natural inference, of course, is that the events are (fictionally) going on now. Ian Mortimer's A Time Traveller's Guide to Medieval England is similarly written in the present tense, and although this is not a novel, it invites us to engage in the fiction that we have actually arrived in the fourteenth century.

There does not seem to be any obvious counterpart on film to the verbal inflexion of the text of a novel, no such thing as 'screen tense'. ${ }^{3}$ Or is there? Consider the use of flashbacks in film where the status of what is being represented (i.e. that the events on screen are fictionally before, rather than after, what one has just been watching) is indicated by a sudden switch from colour to black and white, or by a peripheral lack of focus. (Devices, incidentally, which are not readily reproduced in theatre.) Might these kinds of indicator be the equivalent of linguistic tense? That is, do they indicate a screen tense of pastness, the implication being that in the absence of such indicators, the screen tense is present? In answer, we should note that not all flashbacks are accompanied by any particular manipulation of the screen

3 Though compare Alain Robbe-Grillet's comment: 'on the screen verbs are always in the present tense'. Quoted in Currie (1995), 200.

Manuscrito - Rev. Int. Fil. Campinas, v. 39, n. 4, pp. 315-330, out.-dez: 2016. 
image: a flashback may appear just like any other image, so if the suggestion is that flashbacks are always of the fictional past, then this is not something that can be read off the image. Conversely, images may switch from colour to black and white without there being a flashback, as in if... (Lindsay Anderson, 1969) ${ }^{4}$. And, finally, alterations in the screen image may indicate something other than temporal position: perhaps this is a dream sequence. Quite how changes in the image are to be interpreted will be a contextual matter: one has to attend to the content, and perhaps also to what preceded those images. So, important though filming techniques are, they don't provide any obvious equivalent of verbal inflexion. They do not, therefore, help us to answer the question of where the screen present is in relation to the fictional present (and it is an open question, one to which we will return, whether verbal inflexion in novels actually decides the location of the reading present in relation to the fictional present).

\section{Screen present as fictional past}

Let us start, then, with the suggestion that the screen present always lies in the fictional past. Why might this seem the natural choice? In part, because film fictions look like documentaries (without, in most cases, a narrating voice over). We are to imagine that we are watching a recording of past events. But there is a somewhat deeper reason we might appeal to, and that is that the content of the fiction - what is true in that fiction - is independent of any given presentation of it. The showing of a film is analogous to the performance of a piece of music: neither the fiction nor the composition is constituted by the showing or the performance. After all, something might go wrong with the performance: the percussion might fail to come in on cue. But that makes no difference at all to the composition. Mahler's Fifth, as it might be, is quite unaffected. Similarly, something might go wrong with the showing: the celluloid might get jammed in the projector, or the disk get stuck

\footnotetext{
${ }^{4}$ The reason for using black and white for some sequences in if... were, apparently, technical rather than symbolic. And for others, it was simply a matter of the director's whim!
}

Manuscrito - Rev. Int. Fil. Campinas, v. 39, n. 4, pp. 315-330, out.-dez: 2016. 
in the player. Or the film might accidentally be shown backwards. ${ }^{5}$ But that doesn't affect the content of the fiction. The complete fiction is defined by what's on the whole of the film strip (or encoding on the disk), and the intended order of showing. So the fiction is uniformly determinate, from beginning to end. ${ }^{6}$ That means that the part of the film that will be projected after what is on the screen is just as determinate as what has been projected. And since only the fictional past and present, not the fictional future, is determinate (on the open future hypothesis), the screen present must correspond to the fictional past.

That doesn't provide any very definite location for the fictional present, admittedly. We can't say exactly how remote in the fictional past the screen present is. By the reasoning above, the fictional present must be later than the last event of the film, but we don't know how much later. Or rather, there is no fact of the matter as to how much later it is, for there can hardly be a determinate fictional fact that resists all attempts to discover it (and was never in the author's mind). That is not necessarily a cause for concern. It is determinate that Dorian Gray has hair, but indeterminate how many how many hairs he has on his head. It is not zero, and it is not infinite. Similarly, it is determinate in the fiction that the screen present is some distance from the fictional present, but and determinate that this distance is itself determinate, yet indeterminate what this distance is. But just as it makes no difference to the narrative exactly how many hairs Dorian Gray has, it makes no difference what the distance between screen present and fictional present is - though arguably whether it is zero or non-zero is significant.

However, if the screen image is always taken as representing how things were at a particular point in the past, then this falsifies the hypothesis of the fictional open future. For at the time the events presented were (fictionally) occurring, later events were (on that hypothesis) entirely indeterminate. It was not true at fictional time $t$ that such-and-such an event would occur just after

5 Unusually, this might actually be part of the fiction. In Kurt Vonnegut's Slaughterhouse-Five, the hero, Billy Pilgrim, watches a film of a bombing raid being played backwards. An act of destruction is now seen as a benevolent act of reconstruction.

${ }^{6}$ There will always be some indeterminacy in any fiction, of course, but the point is that there is no systematic correlation of degree of determinacy with time order.

Manuscrito - Rev. Int. Fil. Campinas, v. 39, n. 4, pp. 315-330, out.-dez: 2016. 
$t$. But if we always suppose whatever fictional time we are being presented with is past, then it will be entirely determinate what happened immediately afterwards, even if we are not aware of it (the hypothesis of the open future is a metaphysical thesis, not an epistemological one). This is a consequence of one motivation, noted earlier, for taking the screen present to be in the fictional past, that the fiction is considered to be complete prior to, indeed independently of, any engagement with it. What we are accessing, as the screen images follow one another, is a predetermined narrative. Of course, we can all agree that the representations, in the form of the various stills in the strip of celluloid, or digital information on the disk, are entirely determinate. There is only one way the film is going to unfold. But if we carry that determinacy over to the fictional world, then the open future hypothesis cannot be true of it. According to the fictional open future hypothesis, when the fictional event is fictionally present, what is about to happen is still in the realm of possibility. Now, one could perhaps accept this, but also accept that the presentness of the event, and the consequent indeterminacy of what follows it, is something that is never presented on screen. But for the fictional open future hypothesis, that would mean an awkward gap between the way we experience the screen events (namely as present, and leaving it open as to what will happen), and the fictional facts: that what we are experiencing is actually (or rather fictionally) the past, and so what immediately follows determinate. (Note that, on this model, the fiction of a film is very different from the fiction of a dream, where it would be odd to suppose that we are being presented with past events.)

Thus, on this answer to our question, film fiction would not imitate real life, as the open future hypothesis conceives of it, in which what is about to happen is always indeterminate. The open future proponent is likely to think of this assumption about the future as a key aspect of everyday experience, the very thing that makes the hypothesis so intuitive. If they are right about that, should this not also be part of our experience of watching a film? That is, the assumption of the open future should play a role in film appreciation - it is, in short, aesthetically important. But it can only do that if screen present is also fictionally present. So let us now turn to that approach.

Manuscrito - Rev. Int. Fil. Campinas, v. 39, n. 4, pp. 315-330, out.-dez: 2016. 


\section{Screen present as fictional present}

This is the most tempting answer to our question, as it suggests a direct correspondence between what we might call the tense of experience (we experience fictional events as happening now) and the tense of the fiction. Surely, what we are invited to imagine when watching a film is that the fictional events are happening as we experience them?

Two considerations should make us cautious about leaping to this conclusion, however. One is that, in general, there is no very simple correlation between the temporal properties of the film and the temporal properties of the fiction. The film may present the fictional events in their correct temporal order, but it may not. Flashbacks, already referred to, are an example of anachrony, where presented order does not correspond to fictional order. Some films, such as Pulp Fiction (Quentin Tarentino, 1994), are radically anachronous, where there is no correlation between fictional order and the screen order of the various episodes (though there is such correlation within each episode). Similarly, the duration of fictional events - or what we can infer about their duration - may not be represented by the corresponding duration of screen images. In fact, it is relatively rare for the film to correspond precisely to the time of the fictional events. In Ivan the Terrible (Sergei Eisenstein, 1944, 1958), three hours of screen time represent many years of Ivan's reign (he first appears at his coronation as a young man, and in later sequences as a much older one). There are likely to be gaps, a phenomenon known as 'ellipsis', where some fictional events are not represented at all, but we gather that some period, perhaps an extended one, has passed. With these discrepancies between screen time and fictional time, why should tense be any different?

A second consideration is that not everything it is appropriate to imagine while engaging with a fiction translates into fictional truth. It is entirely appropriate, for example, to imagine that one is seeing and hearing the fictional events. And perceiving such events would imply a spatial and temporal location within the fiction. But this does not make it true that we are, fictionally, in the world of the film.

Nevertheless, despite these reasons for caution in inferring the temporal properties of the fiction from the temporal properties of the screen images, we do have a compelling reason for identifying the screen present with the

Manuscrito - Rev. Int. Fil. Campinas, v. 39, n. 4, pp. 315-330, out.-dez: 2016. 
fictional present, and that is that it deals with the concern raised in the previous section. Given that the open future hypothesis is a deeply entrenched assumption in our view of reality, we naturally import this into our engagement with film - this is an application of what we earlier called the principle of fictional conservatism. So, in watching a film, we take the events that are about to enfold, but which have not yet do so, as indeterminate. Anything can happen. But that can only be the case if what we are watching is fictionally present. We might make clearly anachronous episodes an exception to the rule. If we see a caption 'Three months earlier', or a sequence is preceded by someone narrating events that occurred last year, with a fade into the relevant scenes, or people who had not previously appeared in the film now do so, wearing clearly old-fashioned clothes, etc., then we would be justified in supposing the screen images to be presenting the fictional past. And here there would be no problem in supposing fictional events after the episode in question to be determinate.

Gregory Currie (1995) has argued that the identification of screen present and fictional present (which he calls the 'claim of presentness') is actually in conflict with the phenomenon of anachrony. Taking flashbacks as the example, it seems that the model would have to say one of three things about them, and none is at all plausible:

(1) Flashbacks present the fictional past, rather than the fictional present, and so are exceptions to the model, which still holds good for non-anachronous sequences;

(2) In flashbacks we shift our imagined position in fictional time, so that the fictional present is now earlier than it was when we were looking at the previous image;

(3) Flashbacks always present the contents of someone's (present) memory.

Against the first, Currie points out that images in the flashback look no different (or at least need not look any look any different) from non-flashback images:

When I watch a film that contains anachronous material, I detect no difference between my experience of the images when they present

Manuscrito - Rev. Int. Fil. Campinas, v. 39, n. 4, pp. 315-330, out.-dez: 2016. 
material in standard order and when they deviate from that order. (Currie (1995), 202)

(Essentially, this is the point made earlier that there is no obvious correlate of verbal inflexion in film.) (2) is not, he thinks, true to the phenomenology of film: we don't have the sense of going backwards in fictional time. And (3) seems to place an unwelcome constraint on our interpretation of film. There seems in principle no reason why there cannot be 'mindless fictions', ones which are not about anyone's experiences. Why could there not be flashbacks in such mindless fictions?

We can agree with Currie on (1) and (3), but it should be noted that anyone who identifies screen presentness with fictional presentness is in any case committed to the viewer's position in fictional time shifting, even in nonanachronous episodes, as successive events become fictionally present. So anachrony does not present a special case, forcing a shift we would otherwise not experience.

However, the identification of screen present and fictional present violates what we might think of as another important principle of fiction: that what is true in the fiction is independent of any particular engagement with or presentation of the fiction. (This was part of the motivation, recall, for thinking of the screen images as presenting the fictional past.) For on the current proposal it is the actual screening of the film that generates the fictional truth that such-and-such an event is fictionally present (and, consequently, the fact that earlier events are fictionally past). Without any screening, there would be no tensed fictional facts. And insofar as we identify a fiction with a set of fictional truths, it seems that we must think of the fiction as at least partly constituted by a concrete performance of it. And that means that there is no single fiction for any given film, but rather multiple fictions, one for every screening of the film. Assuming the screening are not precisely successive, different screenings will generate, at any one time, a different set of tensed fictional truths ('The murder is past', 'The uncovering of the murderer is present', etc.). Perhaps the fictional open future proponent can live with this consequence, and jettison the principle that fictional truth is independent of any concrete screening of the film. But what do we say when a film is not been screened? Here there is no mechanism to generate the fictional present. Can we any longer talk of tensed fictional truths in this

Manuscrito - Rev. Int. Fil. Campinas, v. 39, n. 4, pp. 315-330, out.-dez. 2016. 
case? We might revert to our previous model, on which the events in the film are all taken to be past, but the clock would then have to be reset once a new screening had begun. Indeed, it seems that the screening overrides the unscreened film, in terms of fictional truth: what was determinate now ceases to be so. Is this plausible? Perhaps it would be better to think of an unscreened film as not constituting a fiction at all, in the sense of grounding a series of fictional truths, but rather just a set of instructions for generating a fiction when required, just as a musical score is set of instructions for generating, e.g., a symphony. That is, we lose the sense of a fiction as an abstract entity, a set of timeless propositions. Introducing tensed fictional truths this has interesting consequences for the ontology of fiction. These may be surprising, but not necessarily unsustainable. But there is a further reason why screen present cannot be regarded as fictional present, and that is a psychological one.

\section{Screen present as specious present}

So far, we have been assuming that the fictional present, if there is one, would have the same features as the actual present, as the open future hypothesis represents it. That is, just as the actual present marks the boundary between the determinate past and the indeterminate future, so the fictional present would mark a corresponding boundary between the determinate fictional past and the indeterminate fictional future. And we have also been assuming that the screen present, that is, the images projected onto the screen, are capable of marking such a boundary. But there is a compelling reason to think that these two assumptions cannot be held together.

To see the issue, consider this question: what exactly, at any one time, is the image on the screen? It is a pattern of light and dark shapes, which may also be coloured, that is not only visible to us, but also intended to be visible. So any UV light projected onto the screen, whether intentionally or not, would not count as part of the screen image. And if some figure was projected onto the screen too briefly for it to be seen, that too would not count as the screen image, at least for our present purposes, which are to link the screen image to what is fictionally true. The perceivability of the image is essential, for it is the screen image that depicts what is happening in the

Manuscrito - Rev. Int. Fil. Campinas, v. 39, n. 4, pp. 315-330, out.-dez: 2016. 
fiction, and depiction is a perceptual notion. One cannot depict anything by $\mathrm{X}$ Rays, though one could non-depictively encode some information by this means. But for the image to be visible, as we have just noted, it has to last for a minimum amount of time: too brief a stimulus would fail to register on our senses. But also the stimulus itself essentially involves change: the patterns of light reflected or emitted from the screen are distinguishable by their different wavelengths, and this is a temporal phenomenon. An instantaneous state has no wavelength.

The screen present thus corresponds to the experienced present, or what is sometimes called the 'specious present' - 'specious' because it does not correspond with the objective present, which is dimensionless. ${ }^{7}$ And when we describe 'what is going now' in the fiction, we are likely to describe it in terms of events, rather than instantaneous states, which might well defy description. So the sense in which the screen present represents the fictional present is that it represents, not some dimensionless boundary, but rather what would be experienced as present by any fictional observer. This is entirely compatible with the experienced events being fictionally past. (In the actual case, what we experience as present invariably is past, given the time it takes for light and sound to reach us from external events, and for us to register the information. But this is not something we can necessarily import into our experience of fiction.) What we cannot identify the screen present with is any time which is the fictional equivalent of the objective present.

It seems, then, that there are reasons to identify the screen present neither with the fictional past nor with the fictional present, nor the fictional future. What does that leave us with?

\footnotetext{
${ }^{7}$ The argument for the dimensionlessness of the present is essentially St Augustine's. It may be reconstructed as follows: if the present had any duration, it would have earlier and later parts. But then these parts could not all be present. Therefore, whatever is wholly present cannot have duration. For a somewhat fuller reconstruction, and an exploration of the consequences for our understanding of consciousness, see Le Poidevin (2011). The sense of 'specious present' which I am using here is a fairly minimal one: that the experienced present could not correspond precisely to any objective present. But the term is often thought to have further, and more controversial, implications, when it is put to use in explaining how we can perceive change and motion. For critical discussion of this more controversial understanding of the specious present, see, e.g., Phillips (2010).
}

Manuscrito - Rev. Int. Fil. Campinas, v. 39, n. 4, pp. 315-330, out.-dez: 2016. 


\section{Film, fiction and four-dimensionalism}

Suppose we give up the idea that there is such a thing as the fictional present, that fictional truths are all 'tenseless': that is, they are fully articulated by expressions such as 'The theft takes place before the murder', 'The escape from prison coincides with the arrival of the police'; 'The trial takes place on $20^{\text {th }}$ March', and such like. These expressions do not entail that the events in question are past, present or future. That such expressions are adequate to capture actual, as opposed to fictional truth, is the key contention of the metaphysical view of time known as four-dimensionalism, so called because in its denial that time passes in reality, it treats time as being akin (in some certain crucial respects) to space. ${ }^{8}$ In terms of fictional truth, then, the suggestion is that fiction is to be thought of in four-dimensionalist terms. There is no fictional past, present, or future. There are just fictional times, definable either in terms of dates, or in terms of temporal relations (namely, precedence and simultaneity, and metrical relations, such as being three days prior) with other fictional events. Consequently, all fictional times described by the fiction are equally determinate. This view of fictional truth is entirely compatible with our engaging with the fiction in tensed terms. That is, when watching a film, we are perfectly at liberty to imagine what is going on as present, and indeed this may be the correct description of the phenomenology of film watching. But imagining that a fictional event is present does not make it true in the fiction that the event in question is present. This tenseless view of fictional truth avoids the difficulties encountered in the previous sections of fixing the fictional present.

If that is the right account of fiction, where does that leave the proponent of the open future hypothesis? They will, of course, point out that the hypothesis is an account of actual time, not of fictional time, and so does not, directly, at any rate, entail anything about the status of fictional truth.

\footnotetext{
${ }^{8}$ Typically, four-dimensionalism contains a further thesis about the way objects persist through time: that they do so in a way that is analogous to their extension in space. For a full discussion and defence of four-dimensionalism, see Sider (2001). For a discussion of the theory in the context of mental representation, including artistic representation, see Le Poidevin (2007).
}

Manuscrito - Rev. Int. Fil. Campinas, v. 39, n. 4, pp. 315-330, out.-dez. 2016. 
Nevertheless, we can, I think, draw some interesting conclusions.

First, if the open future proponent continues to insist that the hypothesis represents our deeply-entrenched, intuitive view of time, then they would, I think, have to concede that it constitutes a significant exception to what we earlier called the principle of fictional conservatism, that, unless we are given explicit indications to the contrary, we should assume that the world depicted by a particular fiction is, by and large, very similar to our own. If real time has an open future, but fictional time does not (or indeed anything that could be called a future), that is a radical difference between them. So should we modify, perhaps even abandon, the principle of fictional conservatism? Without that principle, we would be left with a lot of indeterminacy in fictional truth, and we would have to be very careful about what inferences to draw about the nature of the fictional world depicted. Alternatively, we might question the degree to which the open future is such a deeply-entrenched part of our ordinary view of time. Is it perhaps that the philosophers have read too much metaphysical significance into ordinary experience and language?

Second (although this is perhaps simply a development of the last point), the abandonment of a fictional past, present and future does not seem to prevent us from treating fictions as temporally structured. That is, we can imagine a time series in ways not defined by a past, present and future. We can, as it were, view fictional time from a 'God's eye' perspective. That suggests that it is not, after all, an essential feature of time that it passes, or has a present which marks the boundary between a determinate past and an indeterminate future. Perhaps, even if time is structured in this way, this is, like its geometry, a contingent feature. If not, then we would have to regard ordinary (but tenseless) narrative fictions as impossible fictions, and this does not seem at all plausible.

I am not proposing that this exercise in aesthetics has the power to defeat a metaphysical view of time. But I hope I have said enough here to demonstrate that the open future hypothesis poses a quite deep aesthetic challenge. 


\section{References}

ACKRILL, J.L. Aristotle's Categories and De Interpretatione, Oxford: Clarendon Press, 1963.

Bourne, C. and CADDick Bourne, E. Time in Fiction, Oxford: Oxford University Press, 2016.

CURRIE, G. Image and Mind: film, philosophy and cognitive science, Cambridge: Cambridge University Press, 1995.

DAINTON, B. Time and Space, $2^{\text {nd }}$ ed., Durham: Acumen, 2010.

LE POIDEVIN The Images of Time; an essay on temporal representation, Oxford: Oxford University Press, 2007. 'The temporal prison', Analysis 71: 456-65, 2011.

LEWIS, D. 'Truth in fiction', American Philosophical Quarterly 15: 37-46, 1978. Postscript to “Time in fiction"”, in D. Lewis, Philosophical Papers Vol. I, 1983. OXFORD: Oxford University Press, 276-80

LuCAS, J.R. The Future, Oxford: Blackwell, 1989.

PHILLIPS, I. 'Perceiving temporal properties', European Journal of Philosophy 18 : 176-202, 2010.

SIDER, T. Four-Dimensionalism: an ontology of persistence and time, Oxford: Oxford University Press, 2001.

Manuscrito - Rev. Int. Fil. Campinas, v. 39, n. 4, pp. 315-330, out.-dez. 2016. 